\title{
Synthesis of a Bruton's Tyrosine Kinase Inhibitor
}
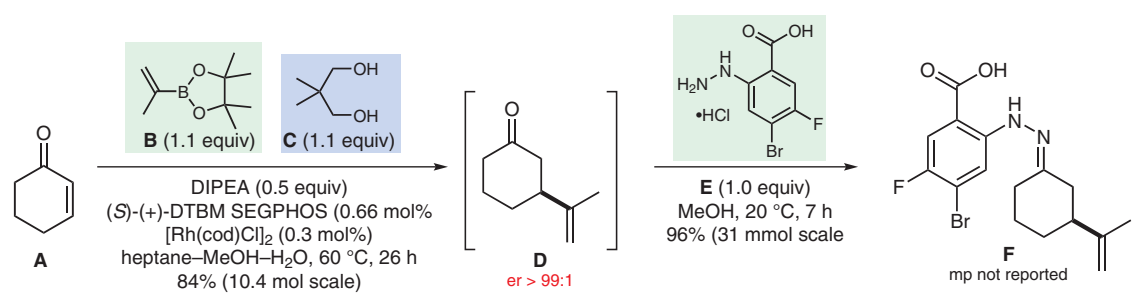

$\mathrm{ZnCl}_{2}$ (1.4 equiv) i-PrOAc, $69.5^{\circ} \mathrm{C}, 71 \mathrm{~h}$ Fischer indole $53 \%(46 \mathrm{mmol}$ scale $)$ synthesis
Gategory

Synthesis of Natural

Products and

Potential Drugs

Key words

Bruton's tyrosine kinase inhibitor

atropisomerism

chirality axes

dynamic

diastereoselection

asymmetric Suzuki-

Miyaura reaction the treatment of rheumatoid arthritis. A major

challenge in the synthesis depicted is the construction of the two axes of chirality marked $\alpha$ and $\beta$. Rotation about these chiral axes gives four possible atropisomeric diastereoisomers. While the higher-energy $\mathrm{C}-\mathrm{C}$ chirality axis $\alpha$ is relatively stable (rotational barrier $28 \mathrm{kcal} / \mathrm{mol}$ ), the lower-energy $\mathrm{C}-\mathrm{N}$ bond $\beta$ (rotational barrier $26 \mathrm{kcal} / \mathrm{mol}$ ) has a rotational half-life of hours to days, with a risk of epimerization.
Comment: The chiral axis $\alpha$ was constructed using an asymmetric Suzuki-Miyaura reaction at $5{ }^{\circ} \mathrm{C}$ to afford biaryl $\mathbf{K}(\mathrm{dr}=16: 1)$. After crystallization from $n-\mathrm{BuOH}, \mathbf{K}$ was obtained with $\mathrm{dr}=65: 1$. The chiral axis $\beta$ was created by crystallization-induced diastereoselection at $25^{\circ} \mathrm{C}$. Compound $\mathbf{N}$ was obtained in 90\% yield and $\mathrm{dr}>99: 1$. Thus the higher barrier diastereoisomer $\mathbf{K}$ acted as a chiral template to construct the stereochemical configuration of lower barrier bond $\beta$. This route delivered $>200 \mathrm{~kg}$ of the target compound $\mathbf{N}$ in $28.3 \%$ overall yield.

SYNFACTS Contributors: Philip Kocienski

Synfacts 2018, 14(09), 0885 Published online: 20.08.2018 Dol: 10.1055/s-0037-1610562; Reg-No.: K05018SF 